\title{
An intercollegiate call for children and young people's mental health
}

\author{
Max Davie consultant community paediatrician and assistant officer for health promotion ${ }^{1}$, Faraz \\ Mughal GP and clinical fellow in mental health ${ }^{2}$
}

${ }^{1}$ Royal College of Paediatrics and Child Health, London WC1X 8SH, UK; ${ }^{2}$ Royal College of General Practitioners, London NW1 2FB, UK

Dubicka and Bullock eloquently explain the current crisis in children and young people's mental health and the inadequacy of current approaches.

The Royal Colleges of General Practitioners, Paediatrics and Child Health, and Psychiatrists acknowledge that mental health is everyone's business and that only concerted and joined up action across all sectors will effect change. As medical professionals we hope to contribute to and lead this process, both in advocacy and by example. To this end the three colleges have committed to five shared principles to improve the care of children and young people with mental illness':

Acknowledgment that the mental health of children and young people is everybody's business and should be supported by a shared vision across all government departments, particularly health, education, and justice

A preventive, multi-agency approach to mental health across all ages, incorporating attention to education for young people and families, social determinants, and health promotion. This should focus on public mental health and early intervention in children and young people, including minimising the need for admission and providing effective crisis services to maintain children and young people in their homes
A system of national and local accountability for the mental health and wellbeing of children and young people, delivered by integrated local area systems

Training and education for the whole children's workforce in their role and responsibilities for mental health of children and young people

More support, both from specialist services and other sectors, for professionals dealing with children and young people who do not meet the referral threshold to a Child and Adolescent Mental Health Service

We call on other organisations across the sectors that interact with children to examine and commit to their responsibilities towards the mental health of children and young people, to mark our commitment, and to hold us to it.

Competing interests: None declared.

Dubicka B, Bullock T. Mental health services for children fail to meet soaring demand. BMJ 2017;359:j4254. doi:10.1136/bmj.j4254 pmid:28963350.

2 RCGP. News: Colleges join forces to make young people's mental health a priority. 21 August 2017 http://www.rcgp.org.uk/news/2017/august/colleges-join-forces-to-makeyoung-peoples-mental-health-a-priority.aspx

Published by the BMJ Publishing Group Limited. For permission to use (where not already granted under a licence) please go to http://group.bmj.com/group/rights-licensing/ permissions 